\title{
Peyzaj ve Süs Bitkileri Programında Okuyan Öğrencilerin Tercih Nedenlerine Göre Mesleğe Bakışlarının İncelenmesi
}

\author{
DOI: $10.26466 /$ opus. 362608
}

\section{Zeynep R. Bozhüyük Ardahanlığlu* - Nihat Karakuş ${ }^{* *}$ - İsmail Çınar ${ }^{* * *}$}

*Dr. Öğr. Ü., Muğla Sıtkı Koçman Üniversitesi Fethiye ASMK Y.O./ Muğla/ Türkiye

E-Posta: zeyneprb@mu.edu.tr ORCID: $\underline{0000-0002-5571-1008}$

${ }^{* *}$ Öğr. Gör., Muğla Sıtkı Koçman Üniversitesi Fethiye ASMK Y.O./ Muğla/ Türkiye

E-Posta: nkarakus@mu.edu.tr $\quad$ ORCID: $\underline{0000-0002-6924-1879}$

***Doç. Dr., Muğla Sıtkı Koçman Üniversitesi Fethiye ASMK Y.O./ Muğla/ Türkiye

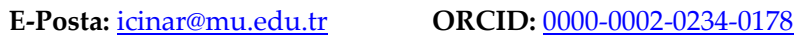

Öz

Bu çalışmada, Peyzaj ve Süs Bitkileri Programı'nda öğrenim gören öğrencilerin tercih nedenlerine göre mesleğe bakışlarının araştıılması amaçlanmıştır. Çalışma, Muğla Sıtkı Koçman Üniversitesi, Fethiye Ali Sttkı Mefharet Koçman Meslek Yüksekokulu'nda 2012-2013, 2013-2014 ve 2014-2015 eğitim-öğretim dönemlerinde Peyzaj ve Süs Bitkileri Programı'nda öğrenim gören öğrencilere anket uygulaması ile yapılmıştır. 2012-2015 yılları arasında programa kayıtlı öğrenci sayısı 113 kişidir ve anket çalışması 90 öğrenciye uygulanmıştır. Anket, bireylerin demografik özellikleri ve mesleğe bakışlarını ölçmek üzere 11 sorudan oluşmaktadır. Ankete katılan 90 öğrencinin sorulara verdiği cevaplar frekans, yüzde, çapraz tablolar ve aritmetik ortalama kullanilarak değerlendirilmiştir. Araştırma sonucunda bireylerin vermiş oldukları cevapların ağırlıklı ortalaması değerlendirildiğinde mesleğe bakış açılarının olumlu olduğu tespit edilmiştir. Mesleğe bakış açısı en olumlu olan ögrrencilerin, mesleği tercih ederken tercih etmiş oldukları mesleği ideali olarak gören öğrenciler olduğu saptanmıştır. Sonrasında ise öğrencilerin tercih nedenlerine göre mesleğe bakış açıları ailesinin isteğgi üzerine tercih edenler ve iş bulma kolaylı̆̆ olduğunu düşünenler şeklinde stralanmaktadır.

Anahtar Kelimeler: Peyzaj ve Süs Bitkileri Programı, Mesleğe bakış, Peyzaj

OPUS (c) Uluslararası Toplum Araştırmaları Dergisi-International Journal of Society Researches ISSN:2528-9527 E-ISSN : 2528-9535

http://opusjournal.net 


\title{
Examining the Viewpoints of the Students Studying at Landscape and Ornamental Plants Department on Their Profession According to Their Reasons for Preferences
}

*

\begin{abstract}
In this study, the purpose was to investigate the viewpoints of the students studying at the Landscape and Ornamental Plants Department on their profession according to their reasons for preferences. The study was conducted in Muğla Sitkı Koçman University, Fethiye Ali Sitkı Mefharet Koçman Vocational High School in 2012-2013, 2013-2014 and 2014-2015 Academic Years by applying questionnaires to the students studying at Landscape and Ornamental Plants Department. The number of the students registered in this program between 2012-2015 was 113, and the questionnaire was applied to 90 students. The Questionnaire consisted of 11 questions to determine the demographical properties and the viewpoints of the students. The answers of 90 students who participated in the questionnaire was assessed with frequency, percentage, cross tables and arithmetic average values. At the end of the study, when the weighted averages of the responses were assessed, it was observed that the viewpoints of the students on their professions were positive. It was determined that the students with the most positive viewpoints were the ones who considered their professions as their ideal profession. The other students were those who preferred their department upon the desire of their families, those who thought that it was easy to find a job after graduating from this department, those who were graduated from Vocational High Schools and wanted to continue an upper level in their profession, those who did not receive adequate points to prefer an undergraduate program, those who wanted to receive undergraduate education by taking the Transition Exam after graduating from their departments, and those who thought that they could be placed in this department according to their scores received from Higher Education Entry Exam.
\end{abstract}

Keywords: Landscape and Ornamental Plants Program, Viewpoint on Profession, Landscape

OPUS (c) Uluslararası Toplum Araştırmaları Dergisi-International Journal of Society Researches ISSN:2528-9527 E-ISSN : 2528-9535

http://opusjournal.net 


\section{Giriş}

"Peyzaj" deyimi Alexander Von Humboldt tarafından 19. Yüzyılın başlarında, bilimsel bir coğrafya terimi olarak literatüre girmiş ve "Bir yeryüzü parçasının total karakteridir" şeklinde tanımlanmıştır (Kader ve Kupik, 2011, s.169). Arazi şekilleri, doğal bitki örtüsü ve topraklar gibi fiziki unsurlar doğal peyzajı oluşturmaktadır. İnsanların bu fiziki unsurları kendi faaliyetleri sonucu şekillendirmesi, değişikliğe uğratması ve kendi karakterini yansıtacak şekilde işlemesi ile de kültürel peyzaj kavramı ortaya çıkmıştır (Arı, 2011, s.314). Doğal ve kültürel bileşenlerin doğru bir şekilde kullanılarak tasarlanması ve planlanması esasına dayanan Peyzaj Mimarlığı mesleğinin temelinde doğal kaynakları korumak vardır. Giderek artan yapılaşma ve kent stresi insanları doğal alanlara yöneltmektedir. Bu nedenle kentsel alanlarda doğal alanlara yakın ortamlar oluşturularak, insanların daha güzel ve sağlıklı bir çevrede yaşama gereksinimlerinin karşılanmaya başlanmasıyla birlikte peyzaj mimarlığı mesleğinin önemi ve mesleki bilinirliği de artmaya başlamıştır.

Peyzaj Mimarlığı, "peyzajı oluşturan doğal ve kültürel bileşenlerin ve çevrelerin koruma-kullanım dengesi gözetilerek; ekolojik, ekonomik, estetik ve işlevsel ölçütlere uygun (olarak) planlaması, tasarımı, onarımı, korunması ve yönetim konularında çalışan" meslek disiplinidir. Peyzaj ve Süs Bitkileri Programları ise peyzaj düzenleme çalışmalarında uygulayıcı olarak görev yapmak üzere nitelikli teknik personel yetiştirmektedir.

Kesim ve Mansuroğlu (2000)'e göre Peyzaj Mimarlığı eğitimi ilk olarak, 1933 y1lında Ankara'da kurulan Yüksek Ziraat Enstitüsü'nde 19421948 yıllarında Bahçe Enstitüsü bünyesinde Bahçe Sanatı ismi ile eğitime başlamıştır. 1971 yılında ise Peyzaj Mimarisi Bölümü olarak eğitime başlamış ve 1973 yılında ilk mezunlarını vermiştir. 1977 yılından sonra bölümün ismi Peyzaj Mimarlığı olarak değiştirilmiştir. 1990 yılından sonra ise mezunlara "Peyzaj Mimarı" unvanı verilmeye başlamıştır (Gül v.d., 2011, s.132). Bu tarihten sonra Peyzaj Mimarları ile uygulayıcılar arasındaki koordinasyonu sağlayarak mesleğin uygulama yönündeki boşluğunu doldurmak üzere sektörün ihtiyaç duyduğu ve aradığı nitelikleri taşıyan meslekler arası bilgi koordinasyon tabanına sahip vasıflı bireyler yetiştirmek üzere Peyzaj ve Süs Bitkileri ön lisans programlarında da, 
Peyzaj ve Süs Bitkileri Teknikerleri yetiştirilmeye başlanmıştır (Karakuş vd., 2014, s.63).

Günümüzde Peyzaj ve Süs Bitkileri Programı, 25 farklı Üniversitenin 27 meslek yüksekokulunda 27 örgün öğretim ve 4 ikinci öğretim olmak üzere aktif olarak eğitim öğretim hayatına devam etmektedir. Bu programdan mezun olanlar, kamu kurumlarında ve özel sektör kuruluşlarında iş imkanı bulmaktadır. 2007 yılında yapılan bir araştırmaya göre Türkiye'deki İl Belediyelerinin Park ve Bahçe Müdürlüklerinde \% 73.4 oranında tekniker bulunmakta ve bunların \% 40.6'sını Peyzaj ve Süs Bitkileri Teknikerlerinin de dahil olduğu Ziraat Teknikerleri oluşturmaktadır (Karakuş vd., 2014 s.63).

Meslek seçimi hem bireysel hem de toplumsal anlamda büyük önem taşımaktadır. Günümüzde, mesleki seçim aşamasında, meslek sayılarının giderek artması ve uzmanlık gerektirmesi nedeniyle bireylerin kendilerine uygun meslek seçmeleri önem kazanmaktadır. Mesleklerin pek çoğunda kişinin başarılı olabilmesi fiziksel özellikleri, mesleği bilerek ve isteyerek seçmiş olmaları ile yakından ilgilidir (Owen vd., 2012, s.135). Bu çalışmada, Peyzaj ve Süs Bitkileri Programı'nda öğrenim gören öğrencilerin tercih nedenlerine göre mesleğe bakışlarının araştırılması amaçlanmıştır.

\section{Materyal ve Yöntem}

Çalışma, Muğla Sıtkı Koçman Üniversitesi Fethiye Ali Sıtkı Mefharet Koçman Meslek Yüksekokulu'nda 2012-2013, 2013-2014 ve 2014-2015 eğitim-öğretim dönemlerinde öğrenim gören öğrenciler ile yapılmıştır. 2012-2015 yılları arasında programa kayıtlı öğrenci sayısı 113 kişidir ve örneklemede bu sayı 90 denekle temsil edilmiştir. Araştırmanın ana materyali Peyzaj ve Süs Bitkileri Programı öğrencileri (bireyler) ve bireylerin demografik özellikleri ve mesleğe bakışlarını ölçmek üzere kullanılan anketler oluşturmaktadır. Atik vd. (2013)'nin, kullanmış olduğu anketlerden yararlanılarak bireylerin demografik özelliklerini belirlemek amacıyla 3 adet soru ve mesleğe bakışlarını ölçmek üzere de 8 adet soru oluşturulmuştur. Ankete katılan öğrencilerin sorulara verdiği cevaplar frekans, yüzde, aritmetik ortalama ve çapraz tablolar kullanılarak değerlendirilmiştir. Aritmetik ortalama hesaplanırken; mesleğin imajı, prog- 
ramı tercih etmeden önce meslek hakkındaki bilgi, mezuniyet sonrası iş bulma kaygısı, mezuniyet sonrası mesleğini yapma durumu, ÖSYS sınavına tekrar girme durumu, mesleği ÖSYS sınavına giren tanıdıklarına tavsiye etme durumu ve eğitim aldıkları programın iyi bir gelecek sağlayacağına ilişkin görüşlerine yönelik sorular dikkate alınmıştır.

\section{Araştırma Bulguları}

Öğrencilerin tercih nedenlerine göre mesleğin imajını nasıl değerlendirdiklerine bakıldığında; meslek lisesinden mezun oldukları için bu programı tercih edenlerin \%80'i mesleğin imajını olumlu bulurken \%6.7'si olumsuz bulmakta \%13.3'ü ise kararsız kalmaktadır. Ailesinin isteği ile bu programı tercih edenlerin ise tamamı mesleğin imajını olumlu bulmaktadır. İş bulma kolaylığı açısından mesleği tercih edenlerin \%91.7'si mesleğin imajını olumlu bulurken \%8.3'ü olumsuz bulmuştur. Mesleği ideali olduğu için tercih edenlerin tamamı mesleğin imajını olumlu bulmuştur. Dikey geçiş sınavı ile lisans programlarına geçmeyi düşündükleri için programı tercih edenlerin \%69.2'si mesleğin imajını olumlu bulurken \%7.7'si mesleğin imajını olumsuz bulmakta ve \%23.1'i karasız olduğunu belirtmiştir. Sınav sonucuna göre aldığı puandan dolayı mesleği tercih edenlerin \%60.9'u mesleğin imajını olumlu bulurken \%39.1'i karasız kalmıştır (Tablo 1).

Öğrencilerin tercih nedenlerine göre meslek hakkındaki bilgi oranlarına bakıldığında; meslek lisesinden mezun oldukları için bu programı tercih edenlerin \%86.7'si meslek hakkında bilgi sahibiyken, \%13.3'ü bilgi sahibi olmadığını belirtmiştir. Ailesinin isteği ile bu programı tercih edenlerin ise tamamı meslek hakkında bilgiye sahiptir. İş bulma kolayl1ğ1 açısından mesleği tercih edenlerin \%58.3'ü meslek hakkında bilgi sahibiyken, \%41.7'si bilgi sahibi olmadığını belirtmiştir. Mesleği ideali olduğu için tercih edenlerin tamamı meslek hakkında bilgiye sahiptir. Dikey geçiş sınavı ile lisans programlarına geçmeyi düşündükleri için programı tercih edenlerin \%69.2'si meslek hakkında bilgi sahibiyken, \%30.8'i bilgi sahibi olmadığını belirtmiştir. Sınav sonucuna göre aldığı puandan dolayı mesleği tercih edenlerin \%56.5'i meslek hakkında bilgi sahibiyken, \%43.5'i bilgi sahibi olmadığını belirtmiştir. 


\begin{tabular}{|c|c|c|c|c|c|c|c|c|c|c|c|c|c|c|c|}
\hline & & & 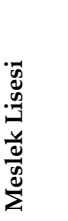 & & 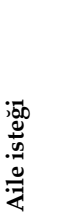 & & & & 节 & & 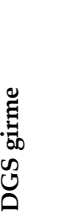 & & $\frac{\sqrt{3}}{\frac{0}{0}}$ & & $\begin{array}{l}\text { בี } \\
\frac{\text { and }}{0} \\
\frac{0}{0}\end{array}$ \\
\hline & & $\mathrm{N}$ & $\%$ & $\mathrm{~N}$ & $\%$ & $\mathrm{~N}$ & $\%$ & $\mathbf{N}$ & $\mathbf{N}$ & $\mathrm{N}$ & $\%$ & $\mathrm{~N}$ & $\%$ & $\mathrm{~N}$ & $\%$ \\
\hline \multirow{4}{*}{$\bar{z}$} & Olumlu & 12 & 80.0 & 4 & 100 & 11 & 73 & 73 & 100 & 9 & 69.2 & 14 & 60.9 & 73 & 81.1 \\
\hline & Olumsuz & 1 & 6.7 & 0 & 0.0 & 1 & 3 & 3 & 0.0 & 1 & 7.7 & 0 & 0.0 & 3 & 3.3 \\
\hline & Kararsızım & 2 & 13.3 & 0 & 0.0 & 0 & 14 & 14 & 0.0 & 3 & 23.1 & 9 & 39.1 & 14 & 15.6 \\
\hline & Toplam & 15 & 100 & 4 & 100 & 12 & 90 & 90 & 100 & 13 & 100 & 23 & 100 & 90 & 100 \\
\hline \multirow{3}{*}{ 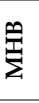 } & Evet & 13 & 86.7 & 4 & 100 & 7 & 69 & 69 & 100 & 9 & 69.2 & 13 & 56.5 & 69 & 76.7 \\
\hline & Hayır & 2 & 13.3 & 0 & 0.0 & 5 & 21 & 21 & 0.0 & 4 & 30.8 & 10 & 43.5 & 21 & 23.3 \\
\hline & Toplam & 15 & 100 & 4 & 100 & 12 & 90 & 90 & 100 & 13 & 100 & 23 & 100 & 90 & 100 \\
\hline \multirow{3}{*}{ 产 } & Evet & 10 & 66.7 & 3 & 75.0 & 8 & 49 & 49 & 30.4 & 6 & 46.2 & 15 & 65.2 & 49 & 54.4 \\
\hline & Hayır & 5 & 33.3 & 1 & 25.0 & 4 & 41 & 41 & 69.6 & 7 & 53.8 & 8 & 34.8 & 41 & 45.6 \\
\hline & Toplam & 15 & 100 & 4 & 100 & 12 & 90 & 90 & 100 & 13 & 100 & 23 & 100 & 90 & 100 \\
\hline \multirow{3}{*}{$\sum_{\sum}^{\infty}$} & Evet & 11 & 73.3 & 4 & 100 & 11 & 78 & 78 & 95.7 & 11 & 84.6 & 19 & 82.6 & 78 & 86.7 \\
\hline & Hayır & 4 & 26.7 & 0 & 0.0 & 1 & 12 & 12 & 4.3 & 2 & 15.4 & 4 & 17.4 & 12 & 13.3 \\
\hline & Toplam & 15 & 100 & 4 & 100 & 12 & 90 & 90 & 100 & 13 & 100 & 23 & 100 & 90 & 100 \\
\hline \multirow{3}{*}{ m } & Özel Sektör & 5 & 33.3 & 2 & 50.0 & 5 & 46 & 46 & 56.5 & 8 & 61.5 & 13 & 56.5 & 46 & 51.1 \\
\hline & Kamu & 10 & 66.7 & 2 & 50.0 & 7 & 44 & 44 & 43.5 & 5 & 38.5 & 10 & 43.5 & 44 & 48.9 \\
\hline & Toplam & 15 & 100 & 4 & 100 & 12 & 90 & 90 & 100 & 13 & 100 & 23 & 100 & 90 & 100 \\
\hline \multirow{3}{*}{ U } & Evet & 5 & 33.3 & 1 & 25.0 & 5 & 42 & 42 & 43.5 & 6 & 46.2 & 15 & 65.2 & 42 & 46.7 \\
\hline & Hayır & 10 & 66.7 & 3 & 75.0 & 7 & 48 & 48 & 56.5 & 7 & 53.8 & 8 & 34.8 & 48 & 53.3 \\
\hline & Toplam & 15 & 100 & 4 & 100 & 12 & 90 & 90 & 100 & 13 & 100 & 23 & 100 & 90 & 100 \\
\hline \multirow{3}{*}{ 垉 } & Evet & 10 & 66.7 & 4 & 100 & 12 & 74 & 74 & 87.0 & 9 & 69.2 & 19 & 82.6 & 74 & 82.2 \\
\hline & Hayır & 5 & 33.3 & 0 & 0.0 & 0 & 16 & 16 & 13.0 & 4 & 30.8 & 4 & 17.4 & 16 & 17.8 \\
\hline & Toplam & 15 & 100 & 4 & 100 & 12 & 90 & 90 & 100 & 13 & 100 & 23 & 100 & 90 & 100 \\
\hline \multirow{3}{*}{ 怘 } & Evet & 13 & 86.7 & 4 & 100 & 10 & 79 & 79 & 100 & 11 & 84.6 & 18 & 78.3 & 79 & 87.8 \\
\hline & Hayır & 2 & 13.3 & 0 & 0.0 & 2 & 11 & 11 & 0.0 & 2 & 15.4 & 5 & 21.7 & 11 & 12.2 \\
\hline & Toplam & 15 & 100 & 4 & 100 & 12 & 90 & 90 & 100 & 13 & 100 & 23 & 100 & 90 & 100 \\
\hline
\end{tabular}

Tablodaki Kisaltmalar:

MI: Mesleğin Imajı, MHB: Meslek Hakkında Bilgi, MSIBK: Mezuniyet Sonrası İş Bulma Kaygısı, MSMY: Mezuniyet Sonrası Mesleğini Yapma, SS: Sektör Seçimi, SG: Sınava Girme, SGTTE: Sinava Giren Tanıdıklarına Tavsiye Etme, PIBGS: Programın İyi Bir Gelecek Sağlayacă̆ı

Öğrencilerin tercih nedenlerine göre mezuniyet sonrası iş bulma kaygılarına yönelik verdiği cevaplara bakıldığında; meslek lisesinden mezun olan öğrencilerin \%66.7'si kaygı sahibiyken, \%33.3'ü herhangi bir kaygi taşımamaktadır. Ailesinin isteği ile bu programı tercih edenlerin \%75'i kaygı sahibiyken, \%25'i herhangi bir kaygı taşımamaktadır. İş bulma kolaylığı açısından mesleği tercih edenlerin \%66.7'si kaygı sahibiyken, \%33.3'ü herhangi bir kaygı taşımamaktadır. Mesleği ideali olduğu için 
tercih edenlerin \%30.4'ü kayg1 sahibiyken, \%69.6's1 herhangi bir kayg1 taşımamaktadır. Dikey geçiş sınavı ile lisans programlarına geçmeyi düşündükleri için programı tercih edenlerin \%46.2'si kaygı sahibiyken, \%53.8'i herhangi bir kaygı taşımamaktadır. Sınav sonucuna göre aldığı puandan dolayı mesleği tercih edenlerin \%65.2'si kaygı sahibiyken, \%34.8'i herhangi bir kaygı taşımamaktadır.

Öğrencilerin tercih nedenlerine göre mezuniyet sonrası mesleği yapma durumlarına bakıldığında; meslek lisesinden mezun oldukları için bu programı tercih edenlerin \%73.3'ü mezuniyet sonrası bu mesleği yapmayı düşünürken, \%26.7'si bu mesleği yapmayı düşünmemektedir. Ailesinin isteği ile bu programı tercih edenlerin tamamı mezuniyet sonrası bu mesleği yapmayı düşünmektedir. İş bulma kolaylığı açısından mesleği tercih edenlerin \%91.7'si mezuniyet sonrası bu mesleği yapmayı düşünürken, \%8.3'ü bu mesleği yapmayı düşünmemektedir. Mesleği ideali olduğu için tercih edenlerin \%95.7'si mezuniyet sonrası bu mesleği yapmayı düşünürken, \%4.3'ü bu mesleği yapmayı düşünmemektedir. Dikey geçiş sınavı ile lisans programlarına geçmeyi düşündükleri için programı tercih edenlerin \%84.6'sı mezuniyet sonrası bu mesleği yapmayı düşünürken, \%15.4'ü bu mesleği yapmayı düşünmemektedir. Sınav sonucuna göre aldığı puandan dolayı mesleği tercih edenlerin \%82.6's1 mezuniyet sonrası bu mesleği yapmayı düşünürken, \%17.4'ü bu mesleği yapmayı düşünmemektedir.

Öğrencilerin tercih nedenlerine göre mezuniyet sonrası çalışmak istedikleri sektöre bakıldığında; meslek lisesinden mezun olup bu programı tercih edenlerin \%33.3'ü özel sektörde, \%66.7'si kamu kuruluşunda çalışmayı istemektedir. Ailesinin isteği ile bu programı tercih edenlerin \%50'si özel sektörde, \%50'si de kamu kuruluşunda çalışmayı istemektedir. İş bulma kolaylığı açısından mesleği tercih edenlerin \%41.7'si özel sektörde, \%58.3'ü kamu kuruluşunda çalışmayı istemektedir. Mesleği ideali olduğu için tercih edenlerin \%56.5'i özel sektörde, \%43.5'i kamu kuruluşunda çalışmayı istemektedir. Dikey geçiş sınavı ile lisans programlarına geçmeyi düşündükleri için programı tercih edenlerin \%61.5'i özel sektörde, \%38.5'i kamu kuruluşunda çalışmayı istemektedir. Sınav sonucuna göre aldığı puandan dolayı mesleği tercih edenlerin \%56.5' $\mathrm{i}$ özel sektörde, \%43.5'i kamu kuruluşunda çalışmayı istemektedir. 
Öğrencilerin tercih nedenlerine göre ÖSYS sınavına tekrar girip başka bir bölümde eğitim-öğretim hayatlarına devam etme durumlarına bakıldığında; meslek lisesinden mezun olup bu programı tercih edenlerin \%33.3'ü tekrar sinava girmeyi isterken, \%66.7'si tekrar sinava girmek istememektedir. Ailesinin isteği ile bu programı tercih edenlerin \%25'i'si tekrar sinava girmeyi isterken, \%75'i tekrar sinava girmek istememektedir. İş bulma kolaylığı açısından mesleği tercih edenlerin \%41.7'si tekrar sinava girmeyi isterken, \%58.3'ü tekrar sinava girmek istememektedir. Mesleği ideali olduğu için tercih edenlerin \%43.5'i tekrar sınava girmeyi isterken, \%56.5'i tekrar sınava girmek istememektedir. Dikey geçiş sınavı ile lisans programlarına geçmeyi düşündükleri için programı tercih edenlerin \%46.2'si tekrar sinava girmeyi isterken, \%53.8'i tekrar sinava girmek istememektedir. Sınav sonucuna göre aldığı puandan dolayı mesleği tercih edenlerin \%65.2'si tekrar sinava girmeyi isterken, \%34.8'i tekrar sinava girmek istememektedir.

Öğrencilerin tercih nedenlerine göre mesleği ÖSYS sinavına giren tanıdıklarına tavsiye etme durumlarına bakıldığında; meslek lisesinden mezun olup bu programı tercih edenlerin \%66.7'si mesleği tavsiye etmeyi düşünürken \%33.3'ü mesleği tavsiye etmeyi düşünmemektedir. Ailesinin isteği ile bu programı tercih edenlerin tamamı mesleği tavsiye etmeyi düşünmektedir. İş bulma kolaylığı açısından mesleği tercih edenlerin tamamı da mesleği tavsiye etmeyi düşünmektedir. Mesleği ideali olduğu için tercih edenlerin \%87'si mesleği tavsiye etmeyi düşünürken, \%13'ü mesleği tavsiye etmeyi düşünmemektedir. Dikey geçiş sınavı ile lisans programlarına geçmeyi düşündükleri için programı tercih edenlerin \%69.2'si mesleği tavsiye etmeyi düşünürken, \%30.8'i mesleği tavsiye etmeyi düşünmemektedir. Sınav sonucuna göre aldığı puandan dolayı mesleği tercih edenlerin \%82.6's1 mesleği tavsiye etmeyi düşünürken, \%17.4'ü mesleği tavsiye etmeyi düşünmemektedir.

Öğrencilerin tercih nedenlerine göre eğitim aldıkları programın kendilerine iyi bir gelecek sağlayacağına ilişkin görüşlerine bakıldı̆̆ında; meslek lisesinden mezun olup bu programi tercih edenlerin \%86.7'si mesleğin kendilerine iyi bir gelecek sağlayacağını düşünürken, \%13.3'ü mesleğin kendilerine iyi bir gelecek sağlayacağını düşünmemektedir. Ailesinin isteği ile bu programı tercih edenlerin tamamı mesleğin kendilerine iyi bir gelecek sağlayacağını düşünmektedir. İş bulma kolaylığı 
açısından mesleği tercih edenlerin \%83.3'ü mesleğin kendilerine iyi bir gelecek sağlayacağını düşünürken, \%16.7'si mesleğin kendilerine iyi bir gelecek sağlayacağını düşünmemektedir. Mesleği ideali olduğu için tercih edenlerin tamamı mesleğin kendilerine iyi bir gelecek sağlayacağını düşünmektedir. Dikey geçiş sınavı ile lisans programlarına geçmeyi düşündükleri için programı tercih edenlerin \%84.6'sı mesleğin kendilerine iyi bir gelecek sağlayacağını düşünürken, \%15.4'ü mesleğin kendilerine iyi bir gelecek sağlayacağını düşünmemektedir. Sınav sonucuna göre aldığı puandan dolayı mesleği tercih edenlerin \%78.3'ü mesleğin kendilerine iyi bir gelecek sağlayacağını düşünürken, \%21.7'si mesleğin kendilerine iyi bir gelecek sağlayacağını düşünmemektedir.

\section{Tartışma ve Sonuç}

İnsanlar gençlik dönemlerinde yetişkin rolünü benimseyerek seçim yapmaya ve özellikle sorumluluk almaya başlamaktadır. Bu seçim doğrultusunda beklenti ve isteklerini gerçekleştireceği ve geçimini sağlayacağı ilgi ve yetenekleri doğrultusunda bir meslek seçmektedirler. Meslek seçimi, bireyin yaşamında çok önemli bir olay olduğundan dolayı meslek seçimi yaparken bir birey aslında kendine belli bir çalışma, belli bir yaşam biçimini seçmekte ve seçtiği bu yolda da başarısıyla kendini kanitlamaya çalışmaktadır. Birey yetenek, ilgi ve istekleri doğrultusunda meslek olarak seçtiği alanda başarılı, verimli ve mutlu olurken, ilgi ve yeteneklerini göz önünde tutmadan rastgele seçim yaptığında başarısız, verimsiz ve mutsuz olmaktadır (Sarıkaya ve Khorshid, 2009, s.394).

Peyzaj ve Süs Bitkileri Programı'nda öğrenim gören öğrencilerin tercih nedenlerine göre mesleğe bakışlarının incelenmesini amaçlayan bu çalışmadan elde edilen bulgulara göre; mesleği ailesinin isteği ile tercih eden ve tercih etmiş oldukları mesleği ideali olarak gören öğrenciler mesleğin imajını diğer nedenlerle tercih eden öğrencilerden daha olumlu olarak görmektedirler ve programı tercih etmeden önce meslek hakkında daha fazla bilgiye sahiptirler. Ayrıca eğitim aldıkları programın iyi bir gelecek sağlayacağını düşünmektedirler. Mesleği ailesinin isteği ile tercih eden öğrenciler mezun olduktan sonra diğer nedenlerle tercih eden ögrencilerden daha fazla mesleğini yapmak istemektedirler. Mesleği ailesinin isteği ve iş bulma kolaylı̆̆ı nedeniyle tercih eden öğrenciler ise 
ÖSYS sınavına giren tanıdıklarına diğer nedenlerle tercih eden öğrencilerden daha fazla mesleği tavsiye etmeyi düşünmektedirler. Mesleği sinav sonucundan dolayı tercih eden öğrenciler de diğer nedenlerle tercih eden öğrencilerden daha fazla tekrar ÖSYS sınavına girmek istemektedirler. Dikey geçiş sınavına girme düşüncesi ile tercih eden öğrenciler diğer nedenlerle tercih eden öğrencilerden daha fazla özel sektörde çalışmak isterken, meslek lisesinden mezun olup sınavsız geçiş yapan öğrenciler ise diğer nedenlerle tercih eden öğrencilerden daha fazla kamuda çalışmak istemektedirler.

Konuyla ilgili yapılmış bir çalışmada ise, seçtikleri bölümleri isteyerek seçen öğrencilerin meslekle ilgili olumlu görüşleri olduğu ve meslek seçimini yapma oranının ise istemeyerek seçen öğrencilerden daha yüksek olduğu, tanıdıklarının tavsiyesi ile mesleğini seçen öğrencilerin ise diğerlerine göre meslekle ilgili olumlu görüşlerinin daha yüksek olduğu belirtilmiştir (Sarıkaya ve Khorshid, 2009, s.414).

Sonuç olarak, bireylerin vermiş oldukları cevapların ağırlıklı ortalaması değerlendirildiğinde, öğrencilerin mesleğe bakış açılarının olumlu olduğu (73.3), ayrıca tercih etmiş oldukları mesleği ideali olarak gören öğrencilerin mesleğe en olumlu bakış açısına sahip oldukları (\%87.0) tespit edilmiştir (Tablo 2). Sonrasında ise öğrencilerin mesleğe bakış açıları mesleği ailesinin isteği ile tercih eden öğrenciler (\%85.7), mezuniyet sonrası iş bulma kolaylığı olduğunu düşünerek tercih eden öğrenciler (\%73.8), meslek lisesinden mezun olup sınavsız geçiş yapan öğrenciler (\%70.5), dikey geçiş sınavına girme düşüncesi ile tercih eden öğrenciler (\%69.2) ve sınav sonucundan dolayı tercih eden öğrenciler (\%61.5) şeklinde sıralanmaktadır.

Çalışmanın sonuçlarına göre ortaya çıkan değerlendirmede, bireyin mesleği ideali olarak seçmesinin ve ailelerinin doğru yönlendirmesinin öğrencilerin mesleğe bakış açılarını olumlu olarak etkilediği görülmektedir. Bu konuda yapılan bir çalışmada; bireyin meslek seçimi üzerinde en güçlü etkinin ailesi olduğunu, öğrencilerin eğitsel ve mesleki tercihlerinin çevrelerindeki önem verdikleri kişilerin ve özellikle ebeveynlerinin algıları doğrultusunda şekillendiğini ifade etmektedir (Owen vd., 2012, s.136). 
Peyzaj ve Süs Bitkileri Programında Okuyan Öğrencilerin Tercih Nedenlerine Göre Mesleğe Bakışlarının İncelenmesi

Tablo 2. Bireylerin mesleğe bakış açılarının aritmetik ortalamasının dă̆ılımı

Tercih Nedeni

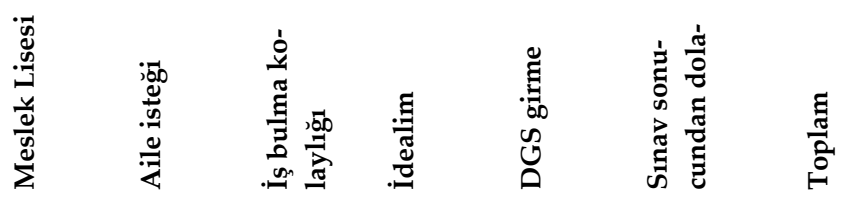

\begin{tabular}{|c|c|c|c|c|c|c|c|c|}
\hline \multirow{3}{*}{ 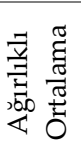 } & & \multirow{2}{*}{$\begin{array}{l}70.5 \\
29.5\end{array}$} & \multirow{2}{*}{$\begin{array}{l}85.7 \\
14.3\end{array}$} & \multirow{2}{*}{$\begin{array}{l}73.8 \\
26.2\end{array}$} & \multirow{2}{*}{$\begin{array}{l}87.0 \\
13.0\end{array}$} & \multirow{2}{*}{$\begin{array}{l}69.2 \\
30.8\end{array}$} & \multirow{2}{*}{$\begin{array}{l}61.5 \\
38.5\end{array}$} & \multirow{2}{*}{$\begin{array}{l}73.3 \\
26.7\end{array}$} \\
\hline & & & & & & & & \\
\hline & $\begin{array}{l}\text { Olumlu } \\
\text { Olumsuz } \\
\text { Toplam }\end{array}$ & $\begin{array}{r}29.5 \\
100.0\end{array}$ & 100.0 & 100.0 & 100.0 & 100.0 & 100.0 & 100.0 \\
\hline
\end{tabular}

Çalışmanın sonuçlarına göre ortaya çıkan değerlendirmede, bireyin mesleği ideali olarak seçmesinin ve ailelerinin doğru yönlendirmesinin öğrencilerin mesleğe bakış açılarını olumlu olarak etkilediği görülmektedir. Nitekim bu konuda yapılan çalışmalara bakıldığında, Clutter (2010) bireyin meslek seçimi üzerinde en güçlü etkinin ailesi olduğunu, Schoon ve Parsons (2002) ise, ailelerin sosyo-ekonomik yapısının çocuklarının mesleki ve eğitsel istekleri ile ilgilerini etkilediğini ifade etmektedir. Reay (2001)'de öğrencilerin eğitsel ve mesleki tercihlerinin çevrelerindeki önem verdikleri kişilerin ve özellikle ebeveynlerinin algıları doğrultusunda şekillendiğini ifade etmektedir (Korkut-Owen vd., 2012).

Geleceğin teminatı olan gençlerin mesleklerini sevmeleri ve yaptıkları meslek seçiminden memnun olmaları, bu tercihi kendi ilgi ve yetenekleri doğrultusunda seçmiş olmaları ile yakından ilgilidir. Ayrıca aile desteğinin hayatın her aşamasında çok önemli olduğu yadsınamaz bir gerçektir. Özellikle gençlerin meslek seçme süreçlerinde ailelerin olumlu yönlendirmelerle gençlere yol göstermeleri gerekmektedir. Bu anlamda ailelere her zamankinden daha fazla görev düşmektedir.

\section{Kaynaklar}

Arı, Y., (2011). Amerikan kültürel coğrafyasında peyzaj kavramı. Doğu Coğrafya Dergisi (13), 314, 311-340. http://edergi.atauni.edu.tr/ataunidcd/article/view/1021006250/1021005 954.

Atik, A., Yılmaz, B., Aslan, F., Ateş, O. ve Taçoral, E., (2013). Peyzaj mimarlığ 1 öğrencilerinin eğitim ve meslekten beklentilerinin inönü 
üniversitesi örneğinde incelenmesi üzerine bir araştırma. İnönü Üniversitesi Sanat ve Tasarm Dergisi, 3(8), 105-122. http://dergipark.ulakbim.gov.tr/inustd/article/view/ 1027000 082/1 027000077.

Gül, A., Örücü, K.Ö., Eraslan, Ş., 2011. Mezun peyzaj mimarlarının eğitim ve öğretimden beklentileri. SDÜ Orman Fakültesi Dergisi, (12), 31-140. http://dergipark.gov.tr/download/article-file/195786.

Kader, Ş. ve Kupik, M., (2011). Peyzaj mimarisinde tasarım ve proje uygulama, 169, http://www.kitapark.com/pdf/peyzajda-tasarim-veuygulama.pdf.

Karakuş, N., Selim, S. ve Çınar, İ., (2014). Peyzaj ve süs bitkileri programının türkiye'deki dağılımının değerlendirilmesi. Türk Bilimsel Derlemeler Dergisi, 7 (1), 62-68. https://azslide.com/trk-bilimselderlemeler-dergisi-7-1-62-68-2014-issn-e-issn-5a4be3501 723dd3756e498d9.html.

Owen, K., F., Kepir, D.D., Özdemir, S., Ulaş, Ö. ve Yılmaz, O., (2012). Üniversite öğrencilerinin bölüm seçme nedenleri. Mersin Üniversitesi Eğitim Fakültesi Dergisi, 8(3) 135-151. http://dergipark.ulakbim.gov.tr/mersinefd/article/view/10020002 63/1002000217.

Sarıkaya, T. ve Khorshid, L., (2009). Üniversite öğrencilerinin meslek seçimini etkileyen etmenlerin incelenmesi: Üniversite öğrencilerinin meslek seçimi. Türk Ĕ̆itim Bilimleri Dergisi Bahar, 7(2), 393423. http://dergipark.gov.tr/download/article-file/256278.

\section{Kaynakça Bilgisi / Citation Information}

Ardahanlığlu, Bozhüyük Z. R., Karakuş, N. ve Çınar İ. (2018). Peyzaj ve süs bitkileri programında okuyan öğrencilerin tercih nedenlerine göre mesleğe bakışlarının incelenmesi. OPUS - Uluslararası Toplum Araştırmaları Dergisi, 8(Gençlik Araştırmaları Özel Sayısı), 318-329. 